\title{
PENGARUH SEPTOPLASTI TERHADAP SUMBATAN HIDUNG
}

\author{
Bestari J Budiman', Effy Huriati ${ }^{1}$, Hafni Bachtiar², Ade Asyari ${ }^{1}$
}

\begin{abstract}
Abstrak
Gejala sumbatan hidung meskipun bukan suatu gejala penyakit yang berat, tetapi dapat menurunkan kualitas hidup dan aktivitas penderita. Salah satu penyebabnya adalah deviasi septum nasi. Pemeriksaan penunjang yang dapat digunakan untuk mendiagnosis dan mengevaluasi gejala sumbatan hidung, diantaranya adalah Nasal Inspiratory Peak Flowmeter (NIPF). Tujuan penelitian ini adalah untuk mengetahui pengaruh septoplasti terhadap sumbatan hidung pada deviasi septum dengan pemeriksaan NIPF. Metode penelitian ini adalah eksperimental studi dengan teknik pre dan post-test design untuk mengetahui gambaran hasil NIPF pada penderita deviasi septum nasi dengan sumbatan hidung. Pengukuran NIPF dilakukan sebelum operasi, minggu ke-2, ke-4 dan ke-6 setelah operasi. Hasil penelitian ini menunjukkan terdapat 11 pasien (93\%) dari 12 pasien secara subyektif mengalami perbaikan sumbatan hidung. Terdapat perubahan sumbatan hidung yang bermakna pada minggu ke-4 $(p=0,01)$, dan ke-6 $(p=0,01)$. Kesimpulan penelitian ini adalah septoplasti dapat memperbaiki sumbatan hidung pada deviasi septum nasi.
\end{abstract}

Kata kunci: sumbatan hidung, deviasi septum, NIPF, septoplasti

\begin{abstract}
Even though nasal congestion is not a severe symptom, it can reduce quality of life and patient's activities. One of the causes of nasal congestion is septal deviation. Diagnostic test that could be used to evaluate nasal congestion is Nasal Inspiratory Peak Flowmeter (NIPF). The objective of this study was to measure the effect of septoplasty to nasal congestion caused by septal deviation with NIPF examination. This research was experimental study by pre and post-test design to evaluate NIPF of patients with nasal congestion due to septal deviation. NIPF was measured before operation surgery, second week, fourth week and sixth week after surgery. The result showed that there were 11 patients (93\%) of 12 patients with decreased of nasal congestion subjectively. There were significant decrease of nasal congestion at fourth week $(p=0.01)$ and sixth week $(p=0.01)$. The conclusion of this study is septoplasty can reduce nasal congestion on septal deviation.
\end{abstract}

Keywords: nasal congestion, septal deviation, NIPF, septoplasty

Affiliasi Penulis: 1. Bagian Telinga Hidung Tenggorok Bedah Kepala Leher (THT-KL) Fakultas Kedokteran Universitas Andalas Padang - RSUP Dr. M. Djamil Padang, 2. Bagian IImu Kesehatan Masyarakat Fakultas Kedokteran Universitas Andalas, Korespondensi: Ade Asyari, Email: adeasyari2@gmail.com, Telp\HP: 08126714429 


\section{PENDAHULUAN}

Deviasi septum nasi didefinisikan sebagai bentuk septum yang tidak lurus di tengah sehingga membentuk deviasi ke salah satu rongga hidung atau kedua rongga hidung yang mengakibatkan penyempitan pada rongga hidung. Bentuk septum normal adalah lurus di tengah rongga hidung tetapi pada orang dewasa biasanya septum nasi tidak lurus sempurna di tengah. Angka kejadian septum yang benar-benar lurus hanya sedikit dijumpai, biasanya terdapat pembengkokan minimal atau terdapat spina pada septum nasi. Bila kejadian ini tidak menimbulkan gangguan respirasi, maka tidak dikategorikan sebagai abnormal. ${ }^{1,2}$

Angka kejadian deviasi septum nasi yang dilaporkan sangat bervariasi. Per-nah dilaporkan di Brazil pada tahun 2004, dimana insiden deviasi septum nasi mencapai 60,3 \% dengan keluhan sumbatan hidung sebanyak 59,9\%. Pada tahun 1995, Min dkk menemukan prevalensi deviasi septum nasi di Korea mencapai $22,38 \%$ dari populasi, dengan penderita yang terbanyak adalah lakilaki. Pada tahun 2002, di Turki, Ugyur dkk melaporkan $15,6 \%$ bayi baru baru lahir dengan persalinan normal mengalami deviasi septum nasi. ${ }^{3}$ Kasus deviasi septum di poliklinik RS. Dr. M Djamil Padang dari April 2010 - April 2011 tercatat 51 kasus deviasi septum dan 20 kasus dilakukan septoplasti.

Deviasi dan dislokasi septum nasi dapat disebabkan oleh gangguan pertumbuhan yang tidak seimbang antara kartilago dengan tulang septum, traumatik akibat fraktur fasial, fraktur nasal, fraktur septum atau akibat trauma saat lahir. Gejala utama adalah hidung ter- sumbat, biasanya unilateral dan dapat intermitten, hiposmia/anosmia dan sakit kepala dengan derajat yang bervariasi. ${ }^{2,4}$

Deviasi yang cukup berat dapat menyebabkan obstruksi hidung yang mengganggu fungsi hidung dan menyebabkan komplikasi atau bahkan menimbulkan gangguan estetik wajah karena tampilan hidung menjadi bengkok. Gejala sumbatan hidung dapat menurunkan kualitas hidup dan aktivitas penderita. Penyebab sumbatan hidung dapat bervariasi dari berbagai penyakit dan kelainan anatomis. Salah satu penyebabnya dari kelainan anatomi yang terbanyak adalah deviasi septum nasi. Tidak semua deviasi septum nasi memberikan gejala sumbatan hidung. Gejala lain yang mungkin muncul dapat seperti hiposmia, anosmia, epistaksis dan sakit kepala. Untuk itu para ahli berusaha membuat klasifikasi deviasi septum nasi untuk memudahkan diagnosis dan penatalaksanaannya. 1,2,4,5

Diagnosis dari gejala sumbatan hidung sangat kompleks dan bervariasi, selain berdasarkan anamnesis dan pemeriksaan fisik juga diperlukan pemeriksaan penunjang untuk pengukuran sumbatan hidung. Skor sumbatan hidung merupakan salah satu parameter untuk menilai suatu sumbatan hidung. Untuk itu diperlukan pemeriksaan penunjang yang dapat digunakan untuk mendiagnosis dan mengevaluasi gejala sumbatan hidung. Diantaranya adalah Nasal Inspiratory Peak Flowmetry (NIPF), Rinomanometri dan Rinometri Akustik. ${ }^{6,7}$

Deviasi septum nasi yang memberikan gejala sumbatan hidung yang berat dan gejala lain yang mengganggu kualitas hidup dapat ditatalaksana dengan mengoreksi septum melalui septo- 
plasti. Saat ini dikenal berbagai teknik septoplasti, antara lain septoplasti tradisional atau yang sering disebut septoplasti konvensional, septoplasti endoskopi dan teknik open book septoplasty. Dimana teknik septoplasti konvensional masih sering dipergunakan dan masih memberikan hasil yang baik. ${ }^{5}$

Tujuan penelitian adalah untuk mengetahui gambaran hasil pengukuran sumbatan hidung sebelum dan sesudah septoplasti pada deviasi septum nasi. Diharapkan hasil penelitian ini dapat meningkatkan pemahaman terhadap sumbatan hidung yang berhubungan dengan deviasi septum yang dapat menjadi landasan untuk penelitian klinis lebih lanjut. Dengan hasil yang didapat tentunya penatalaksanaan deviasi septum nasi dengan sumbatan hidung dapat semakin optimal.

\section{METODE}

Jenis penelitian ini adalah eksperimental study dengan teknik penelitian pre and post-test design untuk mengetahui gambaran hasil Nasal Inspiratory Peak Flowmetry (NIPF) pada penderita deviasi septum nasi dengan sumbatan hidung yang dilakukan septoplasti. Penelitian dilakukan di Bagian Telinga Hidung Tenggorok Bedah Kepala Leher (THTKL) Rumah Sakit (RS) Dr. M Djamil Padang. Penelitian dilakukan dari bulan Mei 2012 sampai jumlah sampel tercapai.

Populasi penelitian adalah penderita deviasi septum yang datang ke poliklinik THT-KL Rumah Sakit Dr. M Djamil Padang dan dilakukan operasi septoplasti. Sampel diambil dengan kriteria inklusi: pasien dengan keluhan sumbatan hidung dan terdiagnosis seba- gai deviasi septum nasi berdasarkan pemeriksaan fisik dan naso-endoskopi, serta berumur 17-60 tahun. Kriteria eksklusi: infeksi saluran nafas atas yang belum teratasi, rinitis alergi, terdapat polip nasi dan jika terdapat tumor sinonasal.

Subjek diambil dari semua penderita dengan keluhan sumbatan hidung dan terdiagnosis deviasi septum nasi yang masuk kriteria inklusi, dan diambil secara berurutan yang berobat ke bagian THT-KL Rumah Sakit Dr. M. Djamil Padang. Persetujuan terlebih dahulu (Informed Consent) dari penderita kemudian anamnesis, pemeriksaan hidung dengan rinoskopi anterior dan nasoendoskopi. Pasien yang didiagnosis dengan deviasi septum nasi bersedia dilakukan operasi septoplasti, kemudian dilakukan pemeriksaan sumbatan hidung dengan NIPF satu hari sebelum septoplasti. Pemeriksaan NIPF ulangan di poliklinik dilakukan minggu ke-2, minggu ke-4, dan minggu ke- 6 setelah dilakukan septoplasti.

Data yang diperoleh dari pemeriksaan dilakukan pengolahan data kuantitatif secara manual dengan komputer program SPSS dalam bentuk tabel dan uji t-test berpasangan. Hasil analisa statistik dinyatakan bermakna bila didapatkan hasil $p<0,05$.

\section{HASIL DAN PEMBAHASAN}

Penelitian ini mendapatkan responden berjenis kelamin laki-laki sejumlah 7 orang $(58 \%)$ dan perempuan 5 orang (42\%). Hal ini sesuai dengan penelitian Han di Korea yang dikutip oleh Oliviera, bahwa penderita deviasi septum terbanyak adalah penderita lakilaki. $^{3}$ 
Hampir semua responden berumur kurang dari 40 tahun yaitu sebanyak 10 orang (83\%) dan hanya 2 orang (17\%) yang berusia lebih dari 40 tahun. Hal ini karena etiologi deviasi septum nasi disebabkan oleh trauma saat kelahiran normal yang mencapai angka $15,6 \%$ dan $15,1 \%$ pada bayi baru lahir secara Caesar. Keluhan sumbatan hidung sering muncul dan dikeluhkan pada umur dewasa muda. ${ }^{3}$

Keluhan hidung tersumbat merupakan keluhan yang sering kita jumpai, terlihat dalam tabel 1. Sumbatan hidung dapat disebabkan karena kelainan mukosa, kelainan struktur jalan nafas hidung seperti deviasi septum nasi dan kolaps jalan nafas. ${ }^{1,8}$

Menurut Bailey seperti yang dikutip Lin SJ dkk, kelainan yang menyebabkan sumbatan hidung adalah deviasi septum nasi, hipertrofi konka, septum perforasi, kolaps valvular, atresia koana, neoplasma, polip nasi, rhinitis alergi, hematom septum, rinitis medikamentosa dan rinitis vasomotor. ${ }^{9}$

Busse $\mathrm{W}$ menggambarkan patologi yang terjadi pada sumbatan jalan nafas meliputi: inflamasi jalan nafas, hiperplasi diikuti hipertropi kelenjar mukus, metaplasi disertai hipertropi sel goblet, hipertrofi otot polos jalan nafas, peningkatan proliferasi pembuluh darah dan edema jalan nafas.Kelainan struktur yang menyebabkan keluhan hidung tersumbat adalah deviasi septum nasi, konka hipertrofi, stenosis ataupun konka bulosa. Deviasi septum nasi melibatkan tulang septum, kartilago atau keduanya. Pada pasien dengan kelainan septum, sisi yang sempit akan mengalami siklus sumbatan hidung yang berbeda, yang menyebabkan perbedaan pada tahanan hidung total, sehingga pasien merasakan sumbatan hidung yang berkala. ${ }^{10}$

Berdasarkan berbagai kepustakaan, patogenesis keluhan sumbatan hidung di pengaruhi oleh berbagai hal, seperti: edema karena inflamasi mukosa, kongesti vaskular, hipersekresi mukosa dan kelainan anatomis seperti deviasi septum nasi. Deviasi septum nasi dapat menyebabkan perubahan pada valve area. Valve area adalah daerah antara septum nasi, bagian anterior dari konka inferior dan bagian bawah dari kartilago lateral inferior. ${ }^{11}$

Tabel 1. Keluhan Subyektif Sebelum Operasi Septoplasti

\begin{tabular}{lcc}
\hline Keluhan & \multicolumn{2}{c}{ Sebelum Septoplasti } \\
& F & $\%$ \\
\hline Hidung tersumbat & 12 & 10 \\
Sakit kepala & 7 & 0 \\
Nyeri di wajah & 4 & 58 \\
Gangguan penghidu & 4 & 33 \\
Hidung berdarah & 4 & 33 \\
Ingus rasa tertelan & 3 & 33 \\
Riwayat trauma & 4 & 25 \\
Telinga terasa & 2 & 33 \\
Denuh & 5 & 17 \\
Susan tidur & 7 & 42 \\
Gangguan aktivitas & & 58 \\
\hline
\end{tabular}

Pada penelitian ini semua pasien deviasi septum nasi (12 orang) mempunyai gejala sumbatan hidung, diikuti oleh keluhan lain adalah keluhan sakit kepala dan gangguan aktifitas masingmasing sebanyak 7 responden (58\%). Hasil ini sesuai dengan laporan Chung dkk pada tahun 2007 bahwa indikasi 
operasi septoplasti pada 106 pasien deviasi septum nasi yang terbanyak adalah sumbatan hidung sebanyak $64,6 \%$, diikuti oleh indikasi untuk memperluas akses dalam melakukan operasi sinus dan nyeri di wajah. ${ }^{12}$ Selain itu, Nawai-seh dkk juga melaporkan 60 tindakan septoplasti dengan indikasi operasi sumbatan hidung sebanyak $91,6 \% .^{13}$ Janardhan dkk melaporkan dari 100 pasien yang dilakukan septoplasti didapatkan keluhan terbanyak adalah sumbatan hidung yaitu 74 pasien. Keluhan lain adalah lendir pada hidung 41 orang, sakit kepala 20 orang, bersin-bersin sebanyak 15 orang dan diikuti keluhan lain seperti epistaksis, post nasal drip, rasa tidak nyaman di tenggorok, mendengkur dan anosmia. $^{14}$

Deviasi septum nasi dapat mengakibatkan terjadinya kelainan pada hidung dan sinus paranasal. Gejala klinis yang dapat timbul adalah sumbatan hidung, epistaksis, nyeri kepala maupun gejala dari rinosinusitis. ${ }^{1,15}$

Septum deviasi juga dapat menyebabkan kolaps dari katup hidung (nasal valve). Katup hidung adalah celah antara ujung kaudal kartilago lateral atas dengan septum hidung. Katup hidung berada lebih kurang $1,3 \mathrm{~cm}$ dari nares dan merupakan segmen yang tersempit serta tahanan terbesar dari jalan nafas hidung. Sesuatu yang memasuki daerah yang sempit ini akan terjadi peningkatan aliran dan peningkatan tekanan interlumen (fenomena Bernoulli). Peningkatan tekanan akibat deviasi septum akan menyebabkan kolapsnya segmen ini pada saat inspirasi. Perubahan sumbatan atau edema sedikit saja, akan meningkatkan tahanan. ${ }^{1,2}$
Terdapat perbaikan yang berarti dalam keluhan subyektif setelah operasi septoplasti. Sebelas responden (93\%) yang mengalami keluhan sumbatan hidung sesudah minggu ke-2 operasi septoplasti, hanya satu pasien yang mengeluhkan sumbatan hidung pada minggu ke-6. Keluhan lain juga berkurang pada minggu ke-6 (tabel 2).

Tabel 2. Keluhan Subyektif Sesudah Operasi Septoplasti

\begin{tabular}{|c|c|c|c|c|c|c|}
\hline \multirow{3}{*}{ Keluhan } & \multicolumn{6}{|c|}{ Setelah Operasi } \\
\hline & \multicolumn{2}{|c|}{ Minggu ke-2 } & \multicolumn{2}{|c|}{ Minggu ke-4 } & \multicolumn{2}{|c|}{ Minggu ke-6 } \\
\hline & f & $\%$ & f & $\%$ & $f$ & $\%$ \\
\hline Hidung tersumbat & 11 & 93 & 2 & 17 & 1 & 8 \\
\hline Sakit kepala & 2 & 17 & 1 & 8 & 1 & 8 \\
\hline Nxeri diwajah & 2 & 17 & - & - & 1 & - \\
\hline Gangguan penghidu & 4 & 33 & 2 & 17 & 1 & 8 \\
\hline Hidung berdarah & 2 & 17 & - & - & - & - \\
\hline Ingus rasa tertelan & 2 & 17 & - & - & - & - \\
\hline Telingaterasa penuh & 1 & 8 & 1 & 8 & - & - \\
\hline Susah tidur & 2 & 17 & - & - & - & - \\
\hline Gangguan aktivitas & 3 & 25 & - & - & - & - \\
\hline
\end{tabular}

Penatalaksanaan deviasi septum nasi sangat tergantung dari keluhan pasien maupun komplikasi yang ditimbulkannya. Septoplasti merupakan prosedur operasi yang dilakukan untuk koreksi deviasi septum nasi. Septoplasti dilakukan jika terdapat keluhan akibat deviasi septum nasi seperti hidung tersumbat, untuk memperbesar akses ke meatus media pada saat melakukan bedah sinus endoskopi fungsional, sakit kepala akibat kontak dengan septum deviasi, epistaksis dan sebagai akses untuk melakukan tindakan operasi tertentu dan alasan kosmetik. Selain itu 
operasi septoplasti dapat memperbaiki daerah katup hidung (valve area) sehingga keluhan yang disebabkan deviasi septum dapat dikurangi bahkan dihilangkan. ${ }^{1,5}$

Keberhasilan operasi septoplasti berdasarkan kepustakaan mencapai $83 \%$, dimana keberhasilan ini tergantung dari kemampuan operator, jenis operasi septoplasti dan kualitas alat operasi. Operasi septoplasti konvensional menyebabkan luka operasi pada mukosa septum. Penyembuhan luka terbagi atas 3 fase, yaitu inflamasi, proliferasi dan remodeling. Faktor yang mempengaruhi waktu dan lamanya masing-masing fase meliputi: iskemia, umur, nutrisi, radiasi, rokok, penyakit sistemik dan jumlah jaringan nekrotik pada luka.Sekitar 2-3 minggu setelah luka awal, akumulasi kolagen telah mencapai kondisi yang stabil.Terdapat pergantian bentuk dari fibril kolagen yang acak menjadi crosslinked fibril yang teratur. Proses ini berlangsung sampai 1 tahun. Jaringan parut berusaha untuk mencapai kekuatan maksimalnya dalam fase ini. ${ }^{16,17}$

Tabel 3. Perbedaan Rata-Rata Nilai NIPF Sebelum dan Sesudah Operasi Septoplasti

\begin{tabular}{cccc} 
& \multicolumn{2}{c}{ Nilai NIPF } & \\
Waktu & Rata-rata & Standar & p \\
\cline { 2 - 3 } & & deviasi & \\
\hline Sebelum operasi & 91,67 & 15,27 & \\
Minggu ke-2 & 114,83 & 14,53 & 0,000 \\
Minggu ke-4 & 126,67 & 23,96 & \\
Minggu ke-6 & 127,08 & 25,09 & \\
\hline
\end{tabular}

Pada tabel 3 terlihat peningkatan rata-rata nilai NIPF dimana sebelum operasi adalah 91,67 dan sesudah operasi minggu ke-2 adalah 114,83, minggu ke-4 adalah 126,67 dan minggu ke-6 dengan nilai rata - rata 127,08. Uji statistik memperlihatkan terdapat hubungan yang bermakna dengan nilai $p=$ 0.000 . Kemudian uji statistik dilanjutkan dengan uji multiple comparasions Bonferroni.

Dari pengukuran NIPF terdapat perbedaan pada nilai rata-rata dan pemeriksaan pada pemeriksaan sebelum operasi dan setelah operasi pada minggu ke-2, minggu ke-4 dan minggu ke-6. Dari hasil uji statistik didapatkan bahwa tidak terdapat perbedaan yang bermakna pada minggu ke-2 $(p=0.05)$. Terdapat perbedaan yang bermakna pada minggu ke-4 dan minggu ke-6 $(p<0.05)$. Karatzanis DA dkk, melaporkan perbandingan hasil sebelum septoplasti dan 28 hari sesudah septoplasti dengan pengukuran rinomanometri, yaitu terdapat peningkatan yang bermakna pada gejala sumbatan hidung. ${ }^{18}$

Bulcun $E$ dkk, melihat efek septoplasti pada gejala sumbatan hidung dan tes fungsi paru-paru dengan menggunakan akustik rinomanometri dan Nasal Expiratory Peak Flowmetry (NEPF), didapatkan perbaikan pada gejala sumbatan hidung, sakit kepala, postnasal drip, fungsi penghidu dan perbaikan tes fungsi paru-paru setelah 8 minggu dilakukan operasi septoplasti. ${ }^{19}$ Sebagian besar kepusta-kaan menyatakan bahwa rata-rata per-baikan sumbatan hidung dan pening-katan kualitas hidup setelah 3 bulan dilakukan septoplasti. ${ }^{20}$ 
Tabel 4. Hasil Uji Statistik Post Hoc Berdasarkan Waktu

\begin{tabular}{lcccc}
\hline & $\begin{array}{c}\text { Sebelum } \\
\text { operasi }\end{array}$ & Minggu ke-2 & Minggu ke-4 & Minggu ke-6 \\
Sebelum operasi & - & 0.050 & 0.001 & 0.001 \\
Minggu ke-2 & 0.050 & - & 0.911 & 0.832 \\
Minggu ke-4 & 0.001 & 0.911 & - & 1.000 \\
Minggu ke-6 & 00.01 & 0.832 & 1.000 & - \\
\hline
\end{tabular}

Uji statistik menunjukkan tidak terdapat perbedaan yang bermakna pada minggu ke-2 dengan nilai $p=0,05$. Terdapat perbedaan yang bermakna pada minggu ke-4 dan minggu ke- 6 dengan nilai $p<0.05$ (tabel 4).

Gambar 1. dibawah ini memperlihatkan peningkatan NIPF sebelum dan sesudah operasi sesuai dengan lamanya waktu. Peningkatan dimulai minggu ke-2, dilanjutkan pada minggu ke-4 dan peningkatan tertinggi pada minggu ke-6.

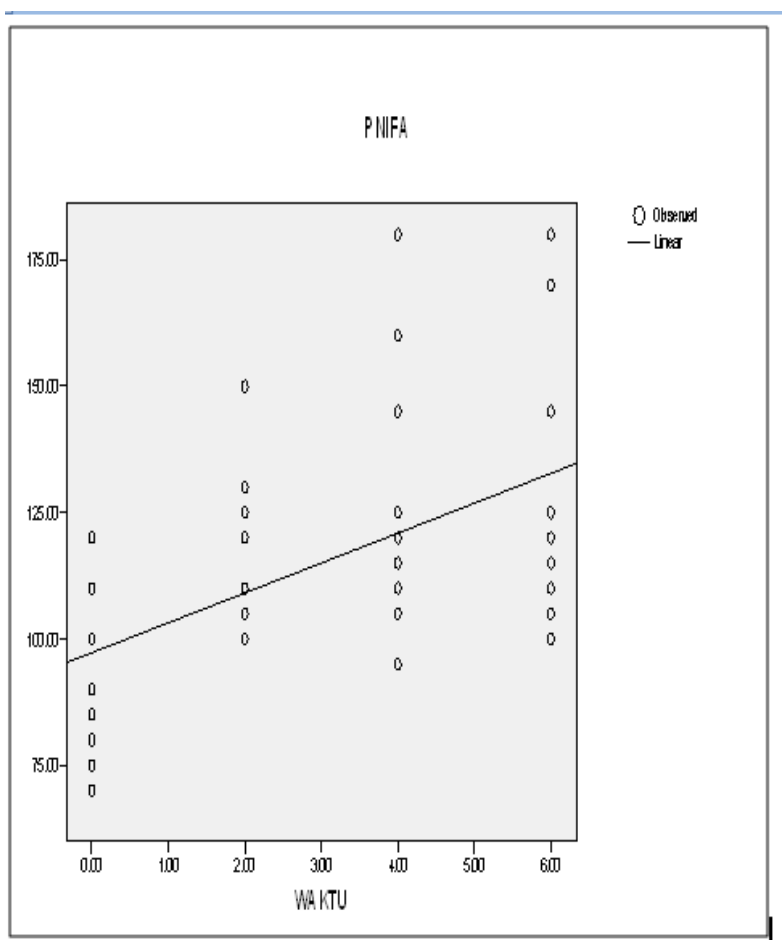

Gambar 1. Perbedaan hasil PNIF berdasarkan waktu

\section{SIMPULAN}

Hasil penelitian ini menyimpulkan terdapat peningkatan hasil NIPF pada pasien deviasi septum sesudah operasi septoplasti sesuai dengan lamanya waktu dalam masa penyembuhan. Ada perubahan sumbatan hidung dari pemeriksaan NIPF yang bermakna secara statistik pada minggu ke-4 dan ke-6 dibandingkan dengan sebelum operasi.

\section{DAFTAR RUJUKAN}

1. Walsh WE, Korn RC. Sinonasal anatomy, function, and evaluation. In Bailey BJ, Johnson JT, editors. Head and Neck Surgery-Otolaryngology. $4^{\text {th }}$ ed. Philadelphia: Lippincott Williams \& Wilkins; 2006. p. 307- 18.

2. Seyhan A, Ozaslan U, Azden S. Threedimentional modeling of nasal septal deviation. Annals of Plast Surg. 2008;60:157-61.

3. Piere de Oliviera AKP, Junior EE, Santos LV. Prevalence of deviated nasal septum in Curitiba, Brazil. Otorhinolaryngology Service of Clinical Hospital of Federal University; 2005:1-8.

4. Becker DG. Septoplasty and turbinate surgery. Asth J Surg. 2003;23(5):393-401.

5. Zhang G, Solomon P, Rival R, Fenton RS, Cole $P$. Nasal airway volume resistance to airflow. Am J Rhinol. 2008;22:371-5.

6. Skadding GK, Lund VJ. Investigative rhinology. $1^{\text {st }}$ Ed. London: Taylor\&Francis; 2004.

7. Teixeire RU, Zappelini CE, Oliveira. Basile LC, Da Costa. Correlation between the peak nasal inspiratory flow and the visual analoque scale before and after using a nasal decongestant. Intl Arch Otorhinolaryngol. 2011;15(2):156-62.

8. Soecipto $D$, Wardani RS. Sumbatan hidung. Dalam Soepardi EA, Iskandar N, penyunting. Buku Ajar IImu Penyakit Telinga Hidung Tenggorok. Jakarta: Balai Penerbit FKUI: 2007. p. 119-22.

9. Lin SJ. Nasal aerodynamics. Medscape 2013. Diakses dari http://emedicine.medscape.com/article/8748 22-overview tanggal 14 Agustus 2013. 
10. Busse W. Pathophysiology of congestion in upper airway congestion implication for lower airway disease. American College Of Allergy, Asthma, and Immunology Annual Meeting in San Antonio, USA 2002.

11. Garcia GJM, Rhee JS, Senior BA, Kimbell JS. Septal deviation and nasal resistance: an investigation using virtual surgery and computational fluid dynamics. Am J Rhinol Allergy. 2010;24(1):46-53.

12. Chung BJ, Batra PS, Citardi MJ, Lanza DC. Endoscopic septoplasty: revisitation of technique, indications, and outcomes. Am J Rhinol. 2007; 21:307-11.

13. Nawaiseh S, Al-Khtoum N. Endoscopic septoplasty: retrospective analysis of 60 cases. J Pak Med Assoc. 2010;60(10):796-8

14. Rao JJ, Kumar ECV, Babu KR, Chowdary VS, Singh J, Rangamani SV. Classification of nasal neptal deviations-relation to sinonasal pathology. Indian $\mathrm{J}$ Otolaryngol and Head Neck Surg. 2005;57(3):199-201.

15. Tahamiler R, Canakcioglu S, Yilmaz S, Dirican A. Expiratory nasal sound analysis as a new method for evaluation of nasal obstruction in patients with nasal septal deviation: comparation of expiratory nasal sound from both deviated and normal nasal cavity. J Laryngol Otol. 2008;122(2):150-4.
16. Gourin CG, Terris DJ. Dynamics of wound healing. In Bailey BJ, Johnson JT, editors. Head and Neck Surgery-Otolaryngology. $4^{\text {th }}$ Ed. Philadelphia: Lippincott Williams \& Wilkins; 2006:197-213.

17. Becker SS, Dobratz EJ, Stowell N, Barker D, Park SS. Revision septoplasty: review of sources of persistent nasal obstruction. Am J Rhinol. 2008;22(4):440-4.

18. Karatzanis DA, Fragiadakis G, Moshandrea J, Zenk J, Iro H, Velegrakis AG. Septoplasty outcome in patients with and without allergic rhinitis. Rhinology.2009;47(4):444-9.

19. Bulcun E, Kazkayasi M, Ekici MA, Tahran FD, Ekici M. Effects of septoplasty on pulmonary function test in patiens with nasal septal deviation. J Otolaryngol Head Neck Surg. 2010;39(2):196-202.

20. Fettman N, Sanford T, Sindwani R. Surgical management of the deviated septum: techniques in septoplasty. Otolaryngol Clin North Am. 2009;42(2):241-52. 